This is an Author's Accepted Manuscript of an article published in Aging \& Mental Health, 14:6, 670-678 (copyright Taylor \& Francis), available online at: http://www.tandfonline.com/10.1080/13607860903311725.

Changes resulting from the publishing process, such as peer review, editing, corrections, structural formatting, and other quality control mechanisms may not be reflected in this document. Changes may have been made to this work since it was submitted for publication.

\title{
PTSD in older bereaved people
}

\author{
Maja O'Connor \\ Department of Psychology, \\ Aarhus University, \\ Denmark.
}

Correspondence concerning this article should be addressed to Maja O'Connor at the Department of Psychology, Aarhus University, Bartholins alle 9, 8000 Århus C, Denmark. Email:maja@psy.au.dk. 
This is an Author's Accepted Manuscript of an article published in Aging \& Mental Health, 14:6, 670-678 (copyright Taylor \& Francis), available online at: http://

\begin{abstract}
Late life bereavement has been associated with psychological problems, mainly depression. A few studies indicated that Posttraumatic Stress Disorder (PTSD) was an important issue in late life bereavement reactions. This study aimed to assess the prevalence of PTSD in recently bereaved older people compared to married controls and to investigate whether the loss of a spouse in old age, in contrast with earlier assumptions, could lead to PTSD. Two hundred and ninety six Danish older bereaved people (mean age 73 years, 113 males) were chosen from national registers and assessed two months post-bereavement. They were compared with a control group of 276 married older people. The prevalence of PTSD and depression were measured through a self-report questionnaire. Results showed that $16 \%$ of the bereaved and $4 \%$ of the control group had a PTSD diagnosis ( $\mathrm{ES}=.35$; Cohen's $\mathrm{d}=.74)$. Additionally, $37 \%$ of the bereaved and $22 \%$ of the control group had mild to severe depression ( $\mathrm{ES}=.19$; Cohen's $\mathrm{d}=.37$ ). The results suggested that late life spousal bereavement result in PTSD with equal frequency to general samples of bereaved persons. Furthermore, the prevalence of PTSD in the first months after bereavement was more elevated than the level of depression. This makes PTSD an important factor when studying late life bereavement reactions.
\end{abstract}

Keywords: PTSD prevalence, late life bereavement, grief, depression. 
This is an Author's Accepted Manuscript of an article published in Aging \& Mental Health, 14:6, 670-678 (copyright Taylor \& Francis), available online at: http://

www.tandfonline.com/10.1080/13607860903311725.

Older people are exposed to a wide variety of losses, for example, a loss in physical functioning, close relatives, siblings and/or partners, changes in residence, and economic independence. Spousal bereavement has a wide range of physical and psychological consequences for the bereaved person (Carr, 2003; Carr, 2004; Silverman et al., 2000).

Uncomplicated grief consists of painful but moderate disruptions to daily life within the first few months post loss and is characterized by disturbances of cognitive, emotional, physical or interpersonal functioning (Bonanno \& Kaltman, 2001). Studies estimate that about $85 \%$ of the bereaved go through what is designated as a normative uncomplicated grief process post loss, while $15 \%$ of the bereaved are likely to have complications in relation to the loss (Bonanno \& Kaltman, 1999). The complication may be expressed in terms of anxiety, depression, and/or PTSD (ibid.), or as Complicated Grief (Jacobs, Mazure \& Prigerson, 2000).

Older bereaved people and PTSD

Losing a spouse in late life is often a very distressing event (Carr, 2004; Moss, Moss, \& Hansson, 2001). In a survey of older bereaved people $72 \%$ indicated that losing their spouse was the most distressing event in their lifetime (Lund, Caserta, \& Dimond, 1993).

Approximately three out of every four people who die, in the United States, exceed 65 years of age (Moss et al., 2001), and within the realm of bereavement there has been some interest in older bereaved people (Stroebe, Hansson, Stroebe, \& Schut, 2001), although the share of publications pertaining to old age bereavement in the bereavement literature appears far from proportional with that of publications pertaining to losses at younger ages.

The Changing Lives of Older Couples study (CLOC) has made a great contribution to the knowledge of old age spousal bereavement. The CLOC has investigated a wide range of bereavement reactions, however investigation of PTSD has been omitted (Burton, Haley \& Small, 2006; Lee \& Carr, 2007). 
This is an Author's Accepted Manuscript of an article published in Aging \& Mental Health, 14:6, 670-678 (copyright Taylor \& Francis), available online at: http://

www.tandfonline.com/10.1080/13607860903311725.

Also within the realm of trauma psychology, the interest in older bereaved people has been very limited. Findings from population based studies, not specifically on bereavement, generally indicate a prevalence rate of approximately $1 \%$ PTSD among older people (age 55-90 years) (Schnurr, Spiro, Vielhauer, Findler, \& Hamblen, 2002; van Zelst, de Beurs, Beekman, Deeg, \& van Dyck, 2003). Studies of older people have mainly focused on reactions to events such as natural disasters and violent war experiences (Ruskin \& Talbott, 1996; Weintraub \& Ruskin, 1999). Recent studies of older people have found a PTSD prevalence ranging from 4-14\% following traumatic experiences such as natural disasters, physical injuries, and threat of illness (Chung, Preveza, Papandreou, \& Prevezas, 2006; Kohn, Levav, Garcia, Machuca, \& Tamashiro, 2005; Lee, Chi, Chung, \& Chou, 2006; Yang et al., 2003). Furthermore, it has been found that older people with PTSD or subclinical PTSD suffer great impairments in their daily lives and have a lower life satisfaction than older persons without such symptoms (Van Zelst et al., 2006).

PTSD and bereavement.

Despite the many age related losses and PTSD being a serious health threat, studies on PTSD in old age bereavement are uncommon. It seems that the main focus is on old age bereavement as an expected life event. It is even alleged that "Although these life events are clearly stressful, they do not approximate traumatic stressors" (Averill \& Beck, 2000, p. 150).

The A1 stressor criterion in the DSM-IV adds a subjective component to the PTSD diagnosis by stating that "the person experienced, witnessed, or was confronted with an event or events that involved actual death actual or threatened death..." (American Psychiatric Association, 1994, p. 467). The A2 criterion of PTSD dictates that an individual must experience feelings of intense fear, helplessness, or horror in response to trauma (ibid.). Furthermore, the following symptoms must be present, B) one or more of five symptoms of persistent re-experiencing of the traumatic event (intrusion, dreams, flash backs, distress or physiological reactivity at exposure), C) three or more of seven symptoms of persistent avoidance (thoughts, feelings, conversations, 
This is an Author's Accepted Manuscript of an article published in Aging \& Mental Health, 14:6, 670-678 (copyright Taylor \& Francis), available online at: http://

www.tandfonline.com/10.1080/13607860903311725.

activities, places) or numbness (inability to recall, diminished interest, detachment from others, restricted affect, sense of foreshortened future), D) two or more of five symptoms of persistent increased arousal (sleep disturbances, irritability, concentration problems, hypervigilance, startle response). In addition, an individual must meet the requirements of criterion E) the duration of the symptoms must exceed 1 month, and F) the disturbance must cause clinically significant distress or impairment in social, occupational, or other important areas of functioning (ibid.).

If the death of a loved one is combined with a feeling of intense fear, helplessness, or horror, the event fulfills criteria A in the DSM-IV definition of PTSD, and can be considered a traumatic event. That is, the loss of a spouse in old age may be considered potentially traumatic if the bereaved person reacts with intense horror, helplessness or fear in relation to the death. The loss of a spouse can also be considered traumatic in the event of death by natural causes.

Co-morbidity plays an important role in PTSD. Particularly in the case of depression and anxiety disorders as such are often strongly correlated with PTSD. It is possible that these disorders are secondary to PTSD following bereavement (McFarlane \& Yehuda, 1996), and that focusing solely on depression, as many studies do, may result in overlooking PTSD as a significant problem. In addition, PTSD is related to serious physical and mental health problems and lower life satisfaction in older people, as well as great expenses for the health services (Van Zelst et al., 2006). Treatment of PTSD has been shown to reduce, for example, depressive symptoms and early identification and treatment of PTSD may help to prevent other psychiatric disorders (Bryant, Moulds, Guthrie, Dang, \& Nixon, 2003). Untreated PTSD may cause chronic symptoms, which can result in disabilities in everyday activities, reduced quality of life, and social withdrawal.

Some publications have addressed PTSD in relation to bereavement (Horowitz, Siegel, Holen, \& Bonanno, 1997; Prigerson, Frank, Kasl, \& Reynolds, 1995) and have noted that complicated bereavement reactions include symptoms clearly separate from those of depression, 
This is an Author's Accepted Manuscript of an article published in Aging \& Mental Health, 14:6, 670-678 (copyright Taylor \& Francis), available online at: http:// www.tandfonline.com/10.1080/13607860903311725.

such as intense intrusive thoughts, avoidance of activity relating to the deceased, yearning and searching for the deceased, loneliness etc. (ibid.). These symptoms appear to overlap with the symptoms of PTSD. In many cases PTSD after bereavement turns into a chronic condition, almost always in combination with depression (Zisook et al., 1998). Still, there is only a limited amount of research available which pertains to PTSD in older bereaved people, therefore further research of issues relating to this field has been requested (Busuttil, 2004).

A few empirical studies addressed the subject. A recent review of associations between mood and anxiety disorders and widowhood found that $12 \%$ suffered from PTSD during the first year of bereavement. None of the reviewed articles targeted older widowed people specifically (Onrust \& Cuijpers, 2006). Brady, Acierno, Resnick, Kilpatrick, \& Saunders (2004) obtained 157 participants from a national women's study and found a higher level of PTSD symptoms but found no difference in depression between widows compared to married older women who had all experienced one previous traumatic event. The type of traumatic event was not identified and the study did not specifically ask the participants about the experience of losing their spouse (ibid.). Melhem et al. (2001) found a concordance of 30\% PTSD in older patients ( $n=23$ ) with traumatic grief. The participants were referred to the study by psychiatrists and psychologists who suspected unresolved grief. No response rate information was available on the two above studies. Zisook, Chentsova-Dutton, \& Shuchter (1998) recruited 350 participants by inviting newly bereaved individuals from the local area to participate. .The study obtained a response rate of $14 \%$. They found that $9-10 \%$ of the bereaved people (mean age $=61$ years) suffered from PTSD two months post loss, and that the disorder was chronic in $40 \%$ of the cases one year after bereavement. Almost all the bereaved participants with chronic PTSD had co-morbid depression (ibid.).

Another study recruited 55 participants through a local home service for older people (response rate $=43 \%$; Elklit \& O'Connor, 2005). The results indicated that $27 \%$ of the bereaved 
This is an Author's Accepted Manuscript of an article published in Aging \& Mental Health, 14:6, 670-678 (copyright Taylor \& Francis), available online at: http://

www.tandfonline.com/10.1080/13607860903311725.

people had PTSD one month post bereavement and 17\% experienced PTSD six months post bereavement (ibid.). However, the study lacked statistical power, especially due to the small sample size. Although the results of the studies pointed to PTSD as a possible reaction to spousal bereavement, further research into the area employing large, representative samples and including control groups is needed to ensure convincing evidence that old age spousal bereavement can be a traumatic experience.

\section{PTSD, Depression and Complicated Grief.}

Depression in relation to bereavement in general has been studied thoroughly (e.g. Boelen \& Prigerson, 2007; Stroebe, Schut, \& Stroebe, 2007). Two recent reviews found a prevalence of major depression of $15 \%$ and $22 \%$ within the first year of general bereavement (Hensley, 2006; Onrust \& Cuijpers, 2006). Additionally, the prevalence of major depression in the recently bereaved was found to diminish across the first two years post bereavement (Rosenzweig, Prigerson, Miller, \& Raynolds, 1997; Zisook, Paulus, Shuchter, \& Judd, 1997). A number of studies on depression and bereavement in old age support the above findings (Harwood, 2001; Ott, Lueger, Kelber, \& Prigerson, 2007; Rosenzweig et al., 1997). It should be emphasized that a major depressive episode according to DSM-IV-TR generally should not be diagnosed within the first two months post loss (Hensley, 2006), while PTSD can be diagnosed 1 month after the event (American Psychiatric Association, 1994).

Lately a considerable amount of work has been conducted on developing the diagnostic criteria of Complicated Grief (CG), as a mental disorder specific to grief reactions complicated enough to be considered pathological (Prigerson et al., 1995; Jacobs et al., 2000). CG is argued to be clearly distinct from other disorders, such as PTSD and depression, and when untreated will be associated with enduring mental and physical health morbidity. CG can be assessed six months after the death of a significant other, and is classified by symptoms of separation distress (e.g. yearning, longing, searching for the deceased) and traumatic distress (e.g. re-experience, avoidance and hyper 
This is an Author's Accepted Manuscript of an article published in Aging \& Mental Health, 14:6, 670-678 (copyright Taylor \& Francis), available online at: http://

www.tandfonline.com/10.1080/13607860903311725.

arousal), the symptoms will have been present at least six months, and will have caused significant impairment in social, occupational, or other important areas of functioning (Prigerson et al., 1995; Jacobs et al., 2000). Recently the diagnosis has been further refined and renamed Prolonged Grief Disorder (Prigerson et al., submitted). It appears that PTSD and CG share many of the same symptoms, and some studies find a high correlation between CG and PTSD (e.g. Cohen, 2006; Ehlers, 2006; Lichtenthal, Creuss \& Prigerson, 2004). While PTSD and CG share some of the same symptoms in relation to intrusion, avoidance, and numbness, CG is conceptually unique from PTSD in relation to separation distress (Lichtenthalet al., 2004), especially in relation to yearning, which is the most common symptom of CG (Prigerson et al., submitted). While CG sometimes involves feelings of helplessness, this is rarely the case with feelings of fear and horror as often seen in PTSD. Furthermore, PTSD often involves more pronounced anxiety, especially when confronted with the threat that is related to the traumatic event, on the other hand, the bereaved people experience separation anxiety with some elements of comfort when confronted with memories of the deceased (Lichtenthal et al., 2004). The findings were supported by two studies by Bonanno et al. (2007) who compared CG, depression and PTSD, and found that CG predicted functioning in the bereaved over and above PTSD and depression. They also found that both PTSD and CG predicted cardiovascular responsivity, however they concluded that PTSD four months post loss predicted increased heart rate when interviewed about the lost relationship, while CG predicted decreased heart rate (Bonanno et al., 2007).

The fact that CG cannot be reliably identified until six months post bereavement (Prigerson et al., submitted), underlines the need for focusing on other, earlier opportunities for identifying pathological reactions to bereavement, making early intervention possible. It has been recommended that traumatic symptoms if present should be treated before depressive symptoms (Bonanno \& Mancini, 2006). The first task, however, must be to identify the prevalence of PTSD in 
This is an Author's Accepted Manuscript of an article published in Aging \& Mental Health, 14:6, 670-678 (copyright Taylor \& Francis), available online at: http:// www.tandfonline.com/10.1080/13607860903311725.

older bereaved people. Further research in this area may shed light on an under-investigated subject and support the development of more efficient preventive initiatives directed towards improving the mental health of older bereaved people.

The objective of this study was to assess the prevalence of PTSD and depression in bereaved older people two months post loss compared to married controls and to investigate whether the loss of a spouse in old age, in contrast with earlier assumptions, can lead to PTSD. Due to the inclusion criteria specifying that participants are two months post loss it was not possible to investigate CG at this point of the study.

\section{Method}

\section{Study procedure}

The full population of persons, aged between 65-80 years, who lived in the county of Aarhus and lost their spouse during the year of 2006 were contacted via the Danish Central Person Register (CPR). Contact was initiated approximately eight weeks after the death of their spouse, at this point individuals were asked to participate in the study. The CPR is a registration system for Danish nationals that collate personal information regarding age, marital status, name of partner, place of residence etc. A matched control group of still married older people was also identified via the CPR for inclusion in the study.

The participants were contacted via an information letter about the study offering either a visit by a trained M.A. student from the Department of Psychology or invited the participants to complete a self-report questionnaire. Participants were randomly allocated into the two groups. After the data collection the participants who received a home visit had the option of an informal, supportive talk with the visitor. The design of the study was longitudinal and conducted across four time points: $2,6,13$, and 18 months post loss. The preliminary, cross-sectional results at baseline two months post loss will be presented here. 
This is an Author's Accepted Manuscript of an article published in Aging \& Mental Health, 14:6, 670-678 (copyright Taylor \& Francis), available online at: http://

www.tandfonline.com/10.1080/13607860903311725.

Respectful reminders were sent by mail. All participants had the option to contact the researcher by phone or by email if needed. Due to the sensitivity of this subject careful ethical considerations were given. The project was accepted by the regional ethics committee.

\section{Participants}

In total 839 older bereaved persons were contacted. Thirty nine were excluded from the study for various reasons, such as death, hospitalization, legal separation from their spouse, dementia etc. Three hundred and thirty (41\%) agreed to participate, but 34 cases were deleted due to unsatisfying data quality (more than 15\% missing items), leaving a total of 296 participants. Eight weeks post loss 169 persons (57\%) received a personal visit and 127 persons (43\%) completed a postal questionnaire.

Of the participants, $113(38 \%)$ were male and $183(62 \%)$ were female with a mean age of 73 years $(S D=4.41$; range 65-81). In the non-response group $117(25 \%)$ were male and $352(75 \%)$ female and the mean age 74 years $(S D=4.55$; range $65-81)$. This means that relatively more men than women chose to participate in the study. A one-way between-groups ANOVA revealed significant demographic differences between participants and non-participants in gender $(F(1,793)=12.18 ; p=0.001)$ and age $(F(1,793)=13.33 ; p<0.0005)$. There were no significant demographic differences between those receiving personal visits or postal questionnaires.

On average the participants had been married for 46 years ( $S D=10.47$; range 3-62), and had an average of eight years of public schooling $(S D=1.56$; range 5-14), and three years $(S D=2.55$; range 0-13) further education. Ninety-five percent had children (mean=2.7; $S D=1.24$; range 1-9). Seventy persons (24\%) lived in villages or rural settings, while 226 persons (76\%) lived in urban settings. Two-hundred-and-fifty-eight persons (87\%) experienced a period of spousal illness preceding the death, and $215(83 \%)$ of these had participated in the daily care of the spouse. One- 
This is an Author's Accepted Manuscript of an article published in Aging \& Mental Health, 14:6, 670-678 (copyright Taylor \& Francis), available online at: http://

www.tandfonline.com/10.1080/13607860903311725.

hundred-and-ninety (66\%) experienced a forewarning of death immediately before the death of their spouse.

Four-hundred-and-eighty-one married older people, who were also identified via the CPR, were included as a control group. The control group received a postal questionnaire. The response rate was $41 \%$. A total of 205 participants were excluded due to unsatisfying data quality (more than $15 \%$ missing items) or recent death of their spouse (41 persons), leaving a total of 276 participants, who completed the questionnaire based on the most significant loss in their lifetime. Sixty nine percent chose loss of a parent, $14 \%$ loss of a sibling, $8 \%$ loss of a previous spouse, $6 \%$ loss of a child, and 5\% loss of a friend. On average 15 months had passed since the loss. Those who chose the loss of a parent as the most distressing loss had significantly lower levels of PTSD as measures by HTQ than those who chose other types of losses $(F(2,275)=5.15, p<.01)$. No significant differences in PTSD were found between the other types of losses. No significant differences in age were found between responding and non-responding or excluded participants within the control group. Due to the selection of still married older people of who relatively more were male, a higher proportion of 138 persons (50\%) of the participants in the control group compared to the bereaved were male. The mean age was 70 years $(S D=4.02$; range $60-81)$.

\section{Measures}

The first part of the baseline questionnaire contained a number of mainly Likert-scale type questions on education, years of marriage, social support, use of medication and alcohol, sense of forewarning before the death of the spouse, feelings of distress, death anxiety and helplessness in relation to the death situation, course of illness of the spouse, religious activities, experience of meaning, mental and physical problems and illnesses, place of the illness and death, and help received from public authorities etc. Data collection was based on self-report questionnaires. 
This is an Author's Accepted Manuscript of an article published in Aging \& Mental Health, 14:6, 670-678 (copyright Taylor \& Francis), available online at: http://

www.tandfonline.com/10.1080/13607860903311725.

The Harvard Trauma Questionnaire-Part IV (Mollica, Capsi-Yavin, Bollini, \& Truong, 1992) was used to estimate the occurrence of PTSD. The HTQ consists of 30 items, rated on a four-point Likert scale $(1=$ not at all; $4=$ very often $)$. The first 16 items of the HTQ contain the three core clusters of PTSD in the DSM-IV: intrusion, avoidance, and arousal. The total HTQ score was based on the first 16 items. In the present study, participants rated the HTQ based on the loss of their spouse while the control group rated the HTQ based on the loss chosen as the most significant in their life-time. Both groups responded in relation to their symptoms during the last month.

The Danish version of the HTQ has been found to be a reliable and valid measure (Bach, 2003). HTQ ratings according to the DSM-III-R diagnostic criteria of PTSD showed an $88 \%$ concordance with interview based estimates of PTSD (Mollica et al., 1992). The internal consistency of the PTSD scale and subscales in the present study were acceptable (Total score: $\alpha=$ .84 ; intrusion: $\alpha=.68$; avoidance: $\alpha=.72$; arousal: $\alpha=.66$ ).

The Beck Depression Inventory (BDI) is a 21-item self-report measure, which assesses cognitive, affective, and somatic symptoms of depression (Beck, Steer, and Garbin, 1988). Each item consists of a set of statements that describe the symptom in question at varying degrees of intensity (range 0-3). Respondents choose the sentence that best describes how they have felt during the past two weeks. The range of the scale is 0-63, with a higher score indicating higher levels of depression. Suggested cut-off scores are: 10-18 = mild depression, 19-29= moderate depression, 30-63 = severe depression (ibid.). A recent review indicated that the internal consistency of the scale is excellent, with $\alpha=.86$ (range .76-.95) for psychiatric populations and $\alpha=.81$ (range .73-.92) for non-psychiatric populations (Beck et al., 1988). In this study, due to ethical reasons, item 21 which pertains to sexuality was omitted, leaving a total of 20 items with a very satisfying internal consistency $(\alpha=.85)$. Due to the exclusion of item 21 the cut-off point was set one point lower than 
This is an Author's Accepted Manuscript of an article published in Aging \& Mental Health, 14:6, 670-678 (copyright Taylor \& Francis), available online at: http://

www.tandfonline.com/10.1080/13607860903311725.

usually recommended (Beck et al. 1988) at 9-17 for mild depression, 18-28 for moderate depression, and 29-63 for severe depression.

Data analysis

After excluding cases with poor data quality which had more than $15 \%$ missing items on a scale, an Expectation Maximization (EM) Algorithm, using SPSS 13 for Windows, was performed. The EM Algorithm was employed to replace missing data on the scales described above. Descriptive statistics were conducted, and reliability measures of the subscales were analyzed. Possible associations between the independent and dependent variables were analyzed by means of the Chi2. Pearson's correlations and cross-tabulations were used to explore relationships between dependent variables. Partial correlations were used to control for possible effects of other confounding variables.

\section{Results}

Based on the results reported on the HTQ, 47 persons (16\%) of older bereaved people fulfilled the criteria for PTSD according to DSM-IV compared to 12 persons (4\%) in the control group. Thirtyseven percent (110 persons) scored 9+ on the BDI-total indicating mild to severe depression compared to $22 \%$ (65 persons) in the control group. An independent samples t-test confirmed that both PTSD $(t(570)=4.58 ; p<.0005)$ and mild to severe depression $(t(570)=4.10 ; p<.0005)$ were significantly more frequent among older bereaved people compared to married controls. There was a medium effect size for HTQ total scores in the older bereaved people compared to the control group ( $\mathrm{ES}=.35$; Cohen's $\mathrm{d}=.74)$. The effect size for the BDI total scores in the bereaved compared to the controls was small (ES=.19; Cohen's d=.37).

A cross-tabulation analysis of the dichotomous variable of full PTSD vs. non PTSD combined with a dichotomous variable of no, mild, moderate, and severe depression was performed. Due to low expected cell frequency, cross-tabulations with severe depression were not reliable. This is why moderate and severe depression was merged into one category. 
This is an Author's Accepted Manuscript of an article published in Aging \& Mental Health, 14:6, 670-678 (copyright Taylor \& Francis), available online at: http://

www.tandfonline.com/10.1080/13607860903311725.

Two of the older bereaved people (5\%) with PTSD had no depression, 27 persons (59\%) also had mild depression, and 17 persons (37\%) had moderate to severe depression (Table 1).

The table also shows that more people with moderate to severe depression (65\%) compared to people with mild depression (32\%) also had PTSD.

Insert table 1

Inter-construct correlations

Correlations between independent and dependent variables among the older bereaved people are described in Table 2a. Control group correlations are described in Table $2 \mathrm{~b}$.

Insert table $2 \mathrm{a}$ and $2 \mathrm{~b}$

When comparing the bereaved group and the control group, the same pattern of correlations was generally identified, though relatively fewer correlations and ones of weaker significance were found in the control group. Further education beyond public schooling, that may be considered an indirect measure of socio-economic status, only provided a significant correlation with years married in the bereaved group. A number of significant correlations were found (see Table $2 \mathrm{a}$ and 2b). Strong, positive correlations between the HTQ and the BDI were found in both groups. The HTQ provided a strong, positive correlation with helplessness, and a medium, positive correlation with distress of death and death-anxiety, in the older bereaved people. The PTSD as measured by the HTQ provided a and a medium, positive correlation with helplessness, and small, positive correlations with distress of death and death-anxiety in the control group. 
Depression as measured by the BDI provided medium, positive correlations with helplessness, distress of death and death-anxiety in the older bereaved people. It provided no significant correlations other than with HTQ in the control group.

Small, negative correlations were found between length of illness in the spouse and both PTSD and depression in the bereaved.

\section{Discussion}

Very few studies investigating PTSD in old age bereavement exist. Therefore, this study is one of the first to look into the issue in detail, using a control group and a large sample size. The results indicate that older bereaved people in this sample are four times more likely to have PTSD than still married controls, demonstrating that late life bereavement is a traumatic experience for some. The correlation between distress in relation to the death situation and symptoms of PTSD (HTQ-total) was much higher for the bereaved (.43) than for the control group (.21), underlining the possible traumatic qualities of old age spousal loss.

As displayed in Table 1 it appeared that a large proportion of individuals with PTSD also had mild depression while a much smaller proportion also had moderate to severe depression. The results indicate that it may be possible to discriminate PTSD from moderate to severe depression, but that the overlap between PTSD and mild depression is too large for a clear discrimination. One plausible explanation is that mild depression may be a common and expected reaction in the first months following bereavement, another possible explanation may be that the BDI due to somatic symptoms often seen in normal aging tends to overestimate depression in older people (Trentini et al. 2005), possibly making discrimination between mild to moderate depression difficult.

The co-morbidity between depression and PTSD increased as depression got more severe, additionally the effect size between the bereaved and the control group was larger for the HTQ than 
This is an Author's Accepted Manuscript of an article published in Aging \& Mental Health, 14:6, 670-678 (copyright Taylor \& Francis), available online at: http://

www.tandfonline.com/10.1080/13607860903311725.

the BDI, underlining that the relative difference between PTSD in the older bereaved people and in the control group was larger than that of depression in the two groups.

In contrast with earlier studies (e.g. Burton et al., 2006) unexpected death did not emerge as a risk factor, and no significant correlations were found between illness/no illness before death and PTSD or depression. The length of illness before death correlated negatively with PTSD and depression in the bereaved. One explanation for this finding may be that the grief reaction was already initiated at the time the terminal diagnosis was given, and that people bereaved after long terminal illness were further along in their grief process, and thus did not present with as many symptoms as bereaved persons who are still in an earlier stage of the grief process.

Longitudinal investigation of the sample may help to understand the high initial PTSD frequency, and help to identify who suffers long-term consequences of old age spousal bereavement. Moreover, it is interesting to note that relatively more widowers than widows participated in the study. This is unusual, since most previous studies had relatively more females participating (Stroebe \& Stroebe, 1989). One possible explanation may be that the cohort of the men in this study born 1925-1940 has different characteristics than cohorts in previous studies. They may have more faith in that results from this type of study can lead to useful knowledge about the topic in question, and respect psychology as a science to a higher degree than seen in other cohorts. Also the fact that the participants were recruited through CPR, a well known public institution, may appeal more to male participants. However, such is only speculative.

The current study has some limitations. First, the response rate of $41 \%$ might be considered relatively low. However, bereaved samples usually have a relatively low response rate in psychological survey studies (Stroebe et al., 2001). At the same time the study targets older people, and response rate is known to decrease with increasing age (Ekwall, Sivberg \& Hallberg, 2004; Kaldenberg, Koenig \& Becker, 1994). Seen in this light the response rate can be considered 
This is an Author's Accepted Manuscript of an article published in Aging \& Mental Health, 14:6, 670-678 (copyright Taylor \& Francis), available online at: http:// www.tandfonline.com/10.1080/13607860903311725.

satisfying. Another explanation for the response rate may be found in the recruitment of participants through the Danish CPR register, which is also one of the major strengths of the study. This type of recruitment makes the sample representative and provides information about the non-participants. Most previous psychological research on late life bereavement and bereavement in general has been based on samples drawn from hospital records, memberships of certain associations, recruitment through obituaries, or active responses to newspaper ads (Stroebe et al., 2001). These types of recruitment may not provide a representative sample.

Another limitation is the small but significant differences in gender and age between the older bereaved people and the control group. The control group contained significantly more males. A probable reason for the gender difference between the two groups is that more older men are married while more older women are widows. The age difference is most likely due to the fact that spousal bereavement usually happens late in life. Ideally, this should have been taken into consideration when sampling for the control group. However, it should be noted that a very significant share of previous studies on PTSD and old age bereavement, or on bereavement in general, do not include a control group (Stroebe et al., 2001). The fact that this study includes a control group must be considered one of its major strengths. A large proportion of the questionnaires received from participants not offered a home visit and especially from the participants in the control group, had to be excluded due to unsatisfying data quality. This finding indicates that home visits to older participants, is a more appropriate, although costly, way of obtaining responses of a satisfying data quality, therefore this study may have benefitted from paying for home visits to all participants both in the bereaved and the control group. The fact that all control group participants received postal questionnaires and therefore involved more exclusions due to unacceptable data quality may be another potential bias. In relation to the control group it may be considered unexpected that the loss chosen as the most significant loss in their lifetime on 
This is an Author's Accepted Manuscript of an article published in Aging \& Mental Health, 14:6, 670-678 (copyright Taylor \& Francis), available online at: http:// www.tandfonline.com/10.1080/13607860903311725.

average had occurred only 15 months ago. However, most interpersonal losses are concentrated in old age. Combined with the fact that bereavement related distress generally is more severe in the first year or two after the loss it is not surprising that relatively recent losses are more often selected as the most significant at the time of responding to the questionnaire.

In addition, the use of the BDI in this sample could be questioned. Due to the many somatic problems in old age, the BDI may over estimate levels of depression when administered to older people (Trentini et al., 2005). Furthermore, item 21 had to be omitted due to the possible discomfort which may have been expressed by the participants if they had to answer an item pertaining to sexuality. Omitting an item may jeopardise the psychometric qualities of a scale. In retrospect, using an alternative scale, for example, the Geriatric Depression Scale, that is designed for older populations and does not include any items on sexuality, may have been a better choice with this type of sample.

Even though the vast majority of older people manage their grief well, PTSD is clearly a possible reaction to the loss for a considerable minority of older bereaved people. With the recommendation in mind that traumatic symptoms if present should be treated before depressive symptoms (Bonanno \& Mancini, 2006), that PTSD may be primary to depression and anxiety disorders following trauma, and that PTSD if untreated could cause serious health problems (McFarlane \& Yehuda, 1996), the issue of PTSD following old age bereavement must be taken into consideration in future bereavement research and in clinical work with older people. The aim would be to generate further knowledge about the prevalence and development of post-bereavement PTSD, and the long-term consequences this may have for the bereaved. Screening based on this knowledge may help to identify who suffers more from PTSD and other disorders following old age spousal bereavement. The identification of such will facilitate disorder specific interventions where help is most needed. The relationship between bereavement-induced PTSD, depression and 
This is an Author's Accepted Manuscript of an article published in Aging \& Mental Health, 14:6, 670-678 (copyright Taylor \& Francis), available online at: http://

www.tandfonline.com/10.1080/13607860903311725.

Complicated Grief, and how the disorders interplay across time is another important issue in future research. With the overlap of symptoms between PTSD and CG in mind, it would be particularly interesting to investigate the relationship between early identified PTSD and later CG. 
This is an Author's Accepted Manuscript of an article published in Aging \& Mental Health, 14:6, 670-678 (copyright Taylor \& Francis), available online at: http://

\section{References}

American Psychiatric Assn, Washington, DC, US. (1994). Diagnostic and statistical manual of mental disorders (4th ed.). Washington, DC: American Psychiatric Publishing, Inc.

Averill, P. M., \& Beck, J. G. (2000). Posttraumatic stress disorder in older adults: A conceptual review. Journal of Anxiety Disorders, 14, 133-156.

Bach, M.E. (2003). En empirisk belysning og analyse af „Emotional Numbing” som eventuel selvstændig faktor i PTSD. Psykologisk Tidsskriftserie, 5(1), 1-199

Beck, A.T., Steer, R.A. and Garbin, M.G. (1988). Psychometric properties of the Beck Depression Inventory: Twenty-five years of evaluation. Clinical Psychology Review, 8(1), 77-100.

Boelen, P. A. \& Prigerson, H. G. (2007): The influence of symptoms of prolonged grief disorder, depression, and anxiety on quality of life among bereaved adults. European Archives of Psychiatry and Clinical Neuroscience, 257, 444-452.

Bonanno, G.A. \& Kaltman, S. (1999): Toward an integrative perspective on bereavement, Psychological Bulletin, 125(6) 760-776.

Bonanno, G.A. \& Mancini, A.D. (Eds.) (2006). Bereavement-Related Depression and PTSD. Evaluating Interventions. In: Barbanel, L. \& Sternberg, R.J. Psychological Interventions in Times of Crisis. New York: Springer Publishing Company.

Bonanno, G.A., Neria, Y., Mancini, A., Coifman, K.G., Litz, B. \& Insel, B. (2007). Is There More to Complicated Grief Than Depression and Posttraumatic Stress Disorder? A Test of Incremental Validity. Journal of Abnormal Psychology, 116(2), 342-351. 
This is an Author's Accepted Manuscript of an article published in Aging \& Mental Health, 14:6, 670-678 (copyright Taylor \& Francis), available online at: http://

Brady, K. L., Acierno, R. E., Resnick, H. S., Kilpatrick, D. G., \& Saunders, B. E. (2004). PTSD symptoms in widowed women with lifetime trauma experiences. Journal of Loss \& Trauma. $9(1), 35-43$.

Bryant, R.A., Moulds, M.L., Guthrie, R.M., Dang, S.T., \& Nixon, R.D.V. (2003). Imaginal exposure alone and imaginal exposure with cognitive restructuring in treatment of posttraumatic stress disorder. Journal of Consulting and Clinical Psychology, 71(4), 706-712.

Burton, A.M., Haley, W.E. \& Small, B.J. (2006). Bereavement after caregiving or unexpected death: Effects on elderly spouses. Aging and Mental Health, 10(13), 319-226.

Busuttil, W. (2004). Presentations and management of post traumatic stress disorder and the elderly: A need for investigation. International Journal of Geriatric Psychiatry, 19(5), 429-439.

Carr, D. (2003). A "good death" for whom? Quality of spouse's death and psychological distress among older widowed persons. Journal of Health \& Social Behavior, 44, 215-232.

Carr, D. (2004). Gender, preloss marital dependence, and older adults' adjustment to widowhood. Journal of Marriage \& Family, 66, 220-235.

Chung, M. C., Preveza, E., Papandreou, K., \& Prevezas, N. (2006). Spinal cord injury, posttraumatic stress, and locus of control among the elderly: A comparison with young and middle-aged patients. Psychiatry: Interpersonal and Biological Processes, 69(1), 69-80.

Cohen, N.L. (2006): Grief and Trauma: An Empirical Investigation of the Construct Overlap and the Psychological and Physiological Functioning of Bereaved Individuals With and Without Complicated Grief. Dissertation Abstracts International: Section B: The Sciences and Engineering, 67(1-B), p. 535 
This is an Author's Accepted Manuscript of an article published in Aging \& Mental Health, 14:6, 670-678 (copyright Taylor \& Francis), available online at: http://

www.tandfonline.com/10.1080/13607860903311725.

Ehlers, A. (2006): Undrstanding and Treating Complicated grief: What Can We Learn from Posttraumatic Stress Disorder, Clinical Psychology: Science and Practice, 13(2), 135-140

Ekwall A, Sivberg B, Hallberg IR. (2004). Dimensions of Informal Care and Quality of Life Among Elderly Family Caregivers. Scandinavian Journal of Caring Science, 18(3):239-48.

Elklit, A., \& O'Connor, M. (2005). Post-traumatic stress disorder in a Danish population of elderly bereaved. Scandinavian Journal of Psychology, 46(5), 439-445.

Harwood, D. (2001). Grief in old age. Reviews in Clinical Gerontology, 11, 167-175.

Hensley, P. L. (2006). A review of bereavement-related depression and complicated grief. Psychiatric Annals, 36(9), 619-626.

Horowitz, M. J., Siegel, B., Holen, A., \& Bonanno, G. A. (1997). Diagnostic criteria for complicated grief disorder. American Journal of Psychiatry, 154(7), 904-910.

Jacobs, S., Mazure, C., \& Prigerson, H. (2000) Diagnostic Criteria of Complicated Grief. Death Studies, 24, 185-199.

Kaldenberg, D.O., Koenig, H.F. \& Becker, B.W. (1994). Mail Survey Response Rate Patterns in a Population of the Elderly: Does Response Deteriorate With Age? Public Opinion Quarterly, 58(1):68-76.

Kohn, R., Levav, I., Garcia, I. D., Machuca, M. E., \& Tamashiro, R. (2005). Prevalence, risk factors and aging vulnerability for psychopathology following a natural disaster in a developing country. International Journal of Geriatric Psychiatry, 20(9), 835-841. 
This is an Author's Accepted Manuscript of an article published in Aging \& Mental Health, 14:6, 670-678 (copyright Taylor \& Francis), available online at: http://

Lee, T. M. C., Chi, I., Chung, L. W. M., \& Chou, K. -. (2006). Ageing and psychological response during the post-SARS period. Aging \& Mental Health, 10(3), 303-311.

Lee, M. \& Carr, D. (2007). Does the Context of Spousal Loss Affect the Physical Functioning of Older Widowed Persons? A Longitudinal Analysis. Research on Aging, 29(5), 457-487.

Lichtentahl, W. G., Cruess, D. G., \& Prigerson, H. G. (2004): A case for establishing complicated grief as a distinct mental disorder in DSM-IV., Clinical Psychology review, 24, 637-662.

Lieberman, M. A. (1992). Limitations of psychological stress model: Studies of widowhood. In M. L. Wykle, \& E. Kahana (Eds.), Stress and health among the elderly (pp. 133-150). New York: Springer Publishing Co.

Lund, D. A., Caserta, M. S., \& Dimond, M. F. (1993). The course of spousal bereavement in later life. In M. S. Stroebe, \& W. Stroebe (Eds.), Handbook of bereavement: Theory, research, and intervention (pp. 240-254). New York, NY, US: Cambridge University Press.

McFarlane, A. C., \& Yehuda, R. A. (1996). Resilience, vulnerability, and the course of posttraumatic reactions. In van der Kolk,Bessel A., \& A. C. McFarlane (Eds.), Traumatic stress: The effects of overwhelming experience on mind, body, and society (pp. 155-181). New York,: Guilford Press.

Melham, N. M., Rosales, C., Karageorge, J., Reynolds, C. F., Frank, E., \& Shear, M. K. (2001). Comorbidity of Axis I disorders in patients with traumatic grief. Journal of Clinical Psychiatry, 62(11), 884-887.

Mollica, R. F., Caspi-Yavin, Y., Bollini, P., \& Truong, T. (1992). The Harvard Trauma Questionnaire: Validating a Cross-Cultural Instrument for Measuring Torture, Trauma, and 
This is an Author's Accepted Manuscript of an article published in Aging \& Mental Health, 14:6, 670-678 (copyright Taylor \& Francis), available online at: http://

Posttraumatic Stress Disorder in Indochinese Refugees. Journal of Nervous \& Mental Disease, $180,111-116$.

Moss, M. S., Moss, S. Z., \& Hansson, R. O. (2001). Bereavement and old age. In M. S. Stroebe, \& R. O. Hansson (Eds.), Handbook of bereavement research: Consequences, coping, and care (pp. 241-160). Washington, DC: American Psychological Association.

Onrust, S. A., \& Cuijpers, P. (2006). Mood and anxiety disorders in widowhood: A systematic review. Aging \& Mental Health, 10(4), 327-334.

Ott, C. H., Lueger, R. J., Kelber, S. T., \& Prigerson, H. G. (2007). Spousal bereavement in older adults: Common, resilient, and chronic grief with defining characteristics. Journal of Nervous and Mental Disease, 195(4), 332-341.

Parkes, C.M. (1996). Bereavement. Studies of Grief in Adult Life ( $3^{\text {rd }}$ ed.). London: Penguin Books.

Prigerson, H. G., Frank, E., Kasl, S. V., \& Reynolds, C. F. (1995). Complicated grief and bereavement-related depression as distinct disorders: Preliminary empirical validation in elderly bereaved spouses. American Journal of Psychiatry, 152, 22-30.

Prigerson, H. G., Maciejewski, P. K., Reynolds, C. F. I., Bierhals, A. J., Newsom, J. T., Fasiczka, A., et al. (1995). Inventory of Complicated Grief: A scale to measure maladaptive symptoms of loss. Psychiatry Research, 59, 65-79.

Prigerson, H.G., Horowitz, M.J., Jacobs, S.C., Parkes, C.M., Aslan, M., Goodkin, K., Raphael, B., Marwit, S.J., Wortman, C., Neimeyer, R.A., Bonanno, G., Block, S.D., Kissane, D., Boelen, P., Maerker, A., Litz, B.T., Johnson, J.G., First, M.B., \& Maciejewski, P.K. (2009) Prolonged 
This is an Author's Accepted Manuscript of an article published in Aging \& Mental Health, 14:6, 670-678 (copyright Taylor \& Francis), available online at: http://

Grief Disorder: Psychometric Validation of Criteria Proposed for DSM-V and ICD-11, PLoS Medicine, 6, 1-10.

Rosenzweig, A., Prigerson, H., Miller, M. D., \& Raynolds, C. F.,. (1997). Bereavement and late-life depression: Grief and its complications in the elderly. Annual Review of Medicine, 48, 421-428.

Ruskin, P. E., \& Talbott, J. A. (1996). Aging and posttraumatic stress disorder. Washington, DC, US: American Psychological Association.

Schnurr, P. P., Spiro, A., III, Vielhauer, M. J., Findler, M. N., \& Hamblen, J. L. (2002). Trauma in the lives of older men: Findings from the normative aging study. Journal of Clinical Geropsychology. 8(3), 175-187.

Silverman, G. K., Jacobs, S. C., Kasl, S. V., Shear, M. K., Maciejewski, P. K., Noaghiul, F. S., et al. (2000). Quality of life impairments associated with diagnostic criteria for traumatic grief. Psychological Medicine, 30(4), 857-862.

Stroebe, M. S., Hansson, R. O., Stroebe, W., \& Schut, H. (Eds.). (2001). Handbook of bereavement research: Consequences, coping, and care. Washington, DC: American Psychological Association.

Stroebe, M. S., \& Stroebe, W. (1989). Who participates in bereavement research? A review and empirical study. Omega: Journal of Death \& Dying, 20(1), 1-29.

Stroebe, M.S., Schut, H. \& Stroebe, W. (2007): Health outcomes of bereavement. Lancet, 370, 1960-1973. 
This is an Author's Accepted Manuscript of an article published in Aging \& Mental Health, 14:6, 670-678 (copyright Taylor \& Francis), available online at: http://

www.tandfonline.com/10.1080/13607860903311725.

Trentine, C. M., de Freitas, X., Flavio, M., Chachamovich, E., da Rocha, N. S., Hirakata, V. N. et al. (2005). The influence of somatic symptoms on the performance of elders in the Beck Depresion Inventory (BDI). Revista Brasileira de Psiquiatria, 27, 119-123.

van Zelst, W. H., de Beurs, E., Beekman, A. T. F., Deeg, D. J. H., \& van Dyck, R. (2003). Prevalence and Risk Factors of Posttraumatic Stress Disorder in Older Adults. Psychotherapy and Psychosomatics, 72(6), 333-342.

Van Zelst, W. H., De Beurs, E., Beekman, A. T. F., Van Dyck, R., \& Deeg, D. D. H. (2006). Wellbeing, physical functioning, and use of health services in the elderly with PTSD and subthreshold PTSD. International Journal of Geriatric Psychiatry, 21(2), 180-188.

Weintraub, D., \& Ruskin, P. E. (1999). Posttraumatic stress disorder in the elderly: A review. Harvard Review of Psychiatry, 7(3), 144-152.

Worden, J.W. (2002): Grief Counselling and Grief Therapy: A Haandbook for the Mental Health Professional ( $3^{\text {rd }}$ ed.). New York: Springer Publishing Company

Yang, Y. K., Yeh, T. L., Chen, C. C., Lee, C. K., Lee, I. H., Lee, L., et al. (2003). Psychiatric morbidity and posttraumatic symptoms among earthquake victims in primary care clinics. General Hospital Psychiatry, 25(4), 253-261.

Zisook, S., Chentsova-Dutton, Y., \& Shuchter, S. R. (1998). PTSD following bereavement. Annals of Clinical Psychiatry, 10(4), 157-163.

Zisook, S., Paulus, M., Shuchter, S. R., \& Judd, L. L. (1997). The many faces of depression following spousal bereavement. Journal of Affective Disorders, 45(1-2), 85-94. 
This is an Author's Accepted Manuscript of an article published in Aging \& Mental Health, 14:6, 670-678 (copyright Taylor \& Francis), available online at: http://

Table 1

\begin{tabular}{|c|c|c|c|c|}
\hline & No depression & Mild depression & $\begin{array}{l}\text { Moderate to severe } \\
\text { depression }\end{array}$ & Total \\
\hline No PTSD & $\begin{array}{l}n=184 \\
74 \%\end{array}$ & $\begin{array}{l}\mathrm{n}=57 \\
23 \%\end{array}$ & $\begin{array}{l}\mathrm{n}=9 \\
4 \%\end{array}$ & $\mathrm{n}=250(85 \%)$ \\
\hline Full PTSD & $\begin{array}{l}\mathrm{n}=2 \\
4 \%\end{array}$ & $\begin{array}{l}\mathrm{n}=27 \\
59 \%\end{array}$ & $\begin{array}{l}\mathrm{n}=17 \\
37 \%\end{array}$ & $\mathrm{n}=46(16 \%)$ \\
\hline Total & $\mathrm{n}=186(63 \%)$ & $\mathrm{n}=84(28 \%)$ & $\mathrm{n}=26(9 \%)$ & $\mathrm{n}=296$ \\
\hline
\end{tabular}


Table $2 \mathrm{a}$

Correlations Between Dependent Variables in the Bereaved. Pearson's Correlations

\begin{tabular}{|c|c|c|c|c|c|c|c|c|c|c|c|c|}
\hline & & 1 & 2 & 3 & 4 & 5 & 6 & 7 & 8 & 9 & 10 & 11 \\
\hline 1 & Gender & & & & & & & & & & & \\
\hline 2 & Further & $.23^{*}$ & & & & & & & & & & \\
\hline & education & & & & & & & & & & & \\
\hline 3 & Years married & -.12 & $-.20 *$ & & & & & & & & & \\
\hline 4 & Illness before & 0.01 & 0.08 & -.09 & & & & & & & & \\
\hline & death & & & & & & & & & & & \\
\hline 5 & Nursed the sick & -.03 & -.08 & .06 & $.33 * *$ & & & & & & & \\
\hline 6 & Length of & .03 & -.10 & .10 & .11 & .11 & & & & & & \\
\hline & illness & & & & & & & & & & & \\
\hline 7 & Forewarning & .02 & -.02 & -.03 & $.46^{* *}$ & $.23^{* *}$ & 0.04 & & & & & \\
\hline 8 & Distress of & .09 & .01 & $-.17 *$ & $-.18 *$ & -.10 & $-.18^{*}$ & - & & & & \\
\hline & death & & & & & & & $.27 * *$ & & & & \\
\hline 9 & Death-anxiety & -.09 & -.07 & .03 & -.05 & .08 & -.15 & .00 & $.24 * *$ & & & \\
\hline 10 & Helplessness & .00 & .01 & $-.17 *$ & -.00 & -.08 & $-.21 *$ & -.03 & $.52 * *$ & $.33 * *$ & & \\
\hline 11 & HTQ total & -.11 & -.07 & .07 & -.14 & -.05 & $-.18 *$ & -.05 & $.43 * *$ & $.43 * *$ & $.57 * *$ & \\
\hline 12 & BDI total & -.12 & -.11 & .09 & -.11 & -.07 & $-.18^{*}$ & -.09 & $.31 * *$ & $.35 * *$ & $.44 * *$ & $.78 * *$ \\
\hline
\end{tabular}

Note. ${ }^{*} \mathrm{P}<0.05$ Bonferroni corrected $* * \mathrm{P}<0.01$ Bonferroni corrected. 
This is an Author's Accepted Manuscript of an article published in Aging \& Mental Health, 14:6, 670-678 (copyright Taylor \& Francis), available online at: http://

www.tandfonline.com/10.1080/13607860903311725.

(Boneferroni cut-offs for correlations were set at $\alpha=0.011(p<0.05)$, and $\alpha=0.0002(\mathrm{P}<0.01)$, thus accounts for the number of tests performed) 
This is an Author's Accepted Manuscript of an article published in Aging \& Mental Health, 14:6, 670-678 (copyright Taylor \& Francis), available online at: http://

www.tandfonline.com/10.1080/13607860903311725.

Table $2 b$

Correlations between Dependent Variables in the Control Group. Pearson's Correlations

$\begin{array}{lllllllllll}1 & 2 & 3 & 4 & 5 & 6 & 7 & 8 & 9 & 10 & 11\end{array}$

\section{Gender}

2 Further

.00

education

3 Years married $-.17^{*}-.02$

4 Illness before $\quad-.03 \quad .03 \quad-.11$

death

5 Nursed the sick $\quad-.22 * \quad .08 \quad-.01 \quad .14$

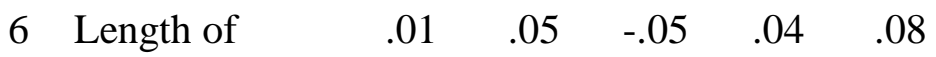

illness

$\begin{array}{llllllll}7 & \text { Forewarning } & -.06 & -.07 & -.01 & .40 * * & .08 & .05\end{array}$

8 Distress of $\quad \begin{array}{llllllll} & -.05 & .07 & .04 & -.16^{*} & -.02 & -.16 & -\end{array}$

death $\quad .31 * *$

9 Death-anxiety $\quad \begin{array}{llllllll}.01 & .05 & .04 & .07 & -.01 & .05 & .07 & .19 *\end{array}$

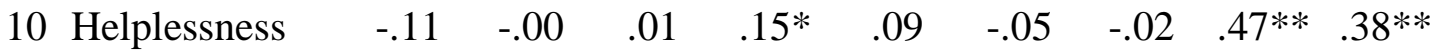

11 HTQ total $\quad \begin{array}{llllllllll}-.06 & -.14 & .09 & .08 & .07 & .05 & -.02 & .21 * & .26 * * & .39 * *\end{array}$

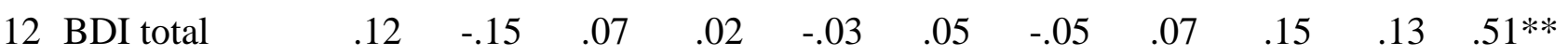

Note. ${ }^{*} \mathrm{P}<0.05$ Bonferroni corrected $* * \mathrm{P}<0.01$ Bonferroni corrected.

(Boneferroni cut-offs for correlations were set at $\alpha=0.011(p<0.05)$, and $\alpha=0.0002(\mathrm{P}<0.01)$, thus accounts for the number of tests performed) 